\title{
LEFT VENTRICULAR ADAPTATION TO AORTIC REGURGITATION IN CONSCIOUS DOGS
}

J. William Gaynor, MD* Michael P. Feneley, MD** Stanley A. Gall, Jr., MD Michael A. Savitt, MD Scott C. Silvestry, MD James W. Davis, PhD J. Scott Rankin, MD*** Donald D. Glower, Jr., MD
Objective: Cardiac failure as a result of valvular heart disease remains a major clinical problem that frequently leads to ventricular dysfunction, myocardial failure, and even death. The development of irreversible myocardial damage may be especially insidious in volume overload as a result of aortic or mitral regurgitation. Methods and results: Left ventricular wall volume, ventricular function, and myocardial performance were assessed in 10 chronically instrumented conscious dogs before and after creation of aortic regurgitation. Left ventricular wall volume was measured by serial echocardiography. Left ventricular function was assessed by total cardiac output, stroke work, the slope of the Frank-Starling relationship, and the slope of the end-systolic pressure-volume relationship. Myocardial performance was assessed by the slope of the myocardial power output versus end-diastolic strain relationship. End-diastolic wall stress and volume both increased acutely and remained elevated after creation of aortic regurgitation. Peak systolic wall stress increased initially ( 1 to 3 weeks) from $336 \pm 30$ to $369 \pm 55 \mathrm{~mm} \mathrm{Hg}$ but returned to control values as left ventricular wall volume increased from $78 \pm 13$ to $88 \pm$ $16 \mathrm{ml}$ after development of compensatory hypertrophy. Left ventricular systolic function remained constant or increased and was maintained initially by increased myocardial performance, which returned to baseline levels after the development of compensatory hypertrophy. Conclusions: Myocardial performance and ventricular function vary independently in aortic regurgitation. Measures of myocardial performance such as the myocardial power output versus end-diastolic strain relationship may be useful in clinical assessment of aortic regurgitation. (J Thorac Cardiovasc Surg 1997;113:149-58)
C ardiac failure as a result of valvular heart disease remains a major clinical problem with chronic pressure or volume overload of the left ventricle frequently leading to ventricular dysfunction, myocardial failure, and even death. ${ }^{1}$ The time course of ventricular adaptation to alterations in loading conditions remains poorly understood and the relative determinants of ventricular hypertrophy versus dilation are unclear. ${ }^{2,3}$ The development of irreversible myocardial damage may be insidious in volume

From the Departments of Surgery, Medicine, and Biomedical Engineering, Duke University Medical Center, Durham, N.C.

Supported by National Institutes of Health grants HL09315, HL46242, and HL29436. Dr. Feneley was supported by a Fulbright Post-doctoral Scholarship, a Neil Hamilton Fairly Fellowship from the National Health and Medical Research Council of Australia, and a Telectronics Overseas Fellowship from the Royal Australasian College of Physicians.

Received for publication Dec. 18, 1995; revisions requested March 19, 1996; revisions received August 13, 1996; accepted for publication August 14, 1996. overload caused by aortic or mitral regurgitation, yet experimental studies of volume overload have produced conflicting results as to whether intrinsic myocardial performance is decreased, increased, or unchanged. ${ }^{1,2,4-8}$

The current study was designed to investigate the early left ventricular adaptive response to aortic regurgitation. Because the severity of volume overload may alter the adaptive response of the left ventricle, mild to moderate aortic regurgitation was

Address for reprints: J. William Gaynor, MD, Pediatric Cardiothoracic Surgery, The Children's Hospital of Philadelphia, Philadelphia, PA 19104.

*Current address: Pediatric Cardiothoracic Surgery, The Children's Hospital of Philadelphia, Philadelphia, Pa.

** Current address: Department of Cardiology, St. Vincent's Hospital, Sydney, Australia.

${ }^{* * *}$ Current address: St. Thomas Medical Plaza West, Nashville, Tenn.

Copyright (C) 1997 by Mosby-Year Book, Inc.

$0022-5223 / 97 \$ 5.00+0 \quad \mathbf{1 2 / 1 / 7 7 3 2 5}$ 


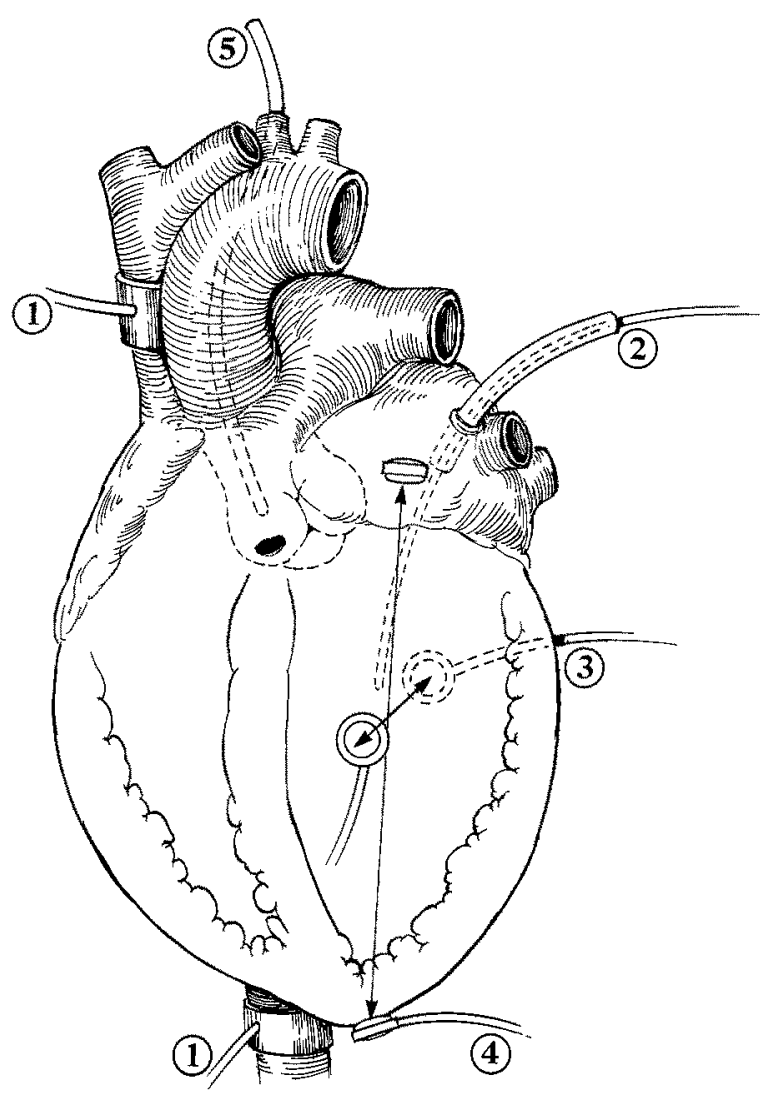

Fig. 1. Left ventricular preparation with pneumatic vena caval occluders (1), silicone rubber introducers in left atrium (2) and pleural space (not shown), dimension transducers across left ventricular minor (3) and major (4) axis diameters, and ascending aortic catheter (5) used to create aortic regurgitation by aortic valve cusp perforation.

created in an attempt to mimic the gradual onset frequently observed clinically. Chronically instrumented conscious dogs were used to eliminate the effects of anesthesia and open-chest preparations. Left ventricular volume and wall mass were measured with use of an integrated technique of sonomicrometry and echocardiography. Intrinsic myocardial performance was measured by the slope of the myocardial power output versus end-diastolic strain relationship. ${ }^{9}$

\section{Methods}

Experimental preparation and data acquisition. All animal studies were done in accordance with guidelines described in the National Institutes of Health's "Guide for the Care and Use of Laboratory Animals" (DHHS Publication No. [NIH] 85-23, revised 1985). Ten adult dogs weighing 18 to $25 \mathrm{~kg}$ were premedicated with cefazolin (1
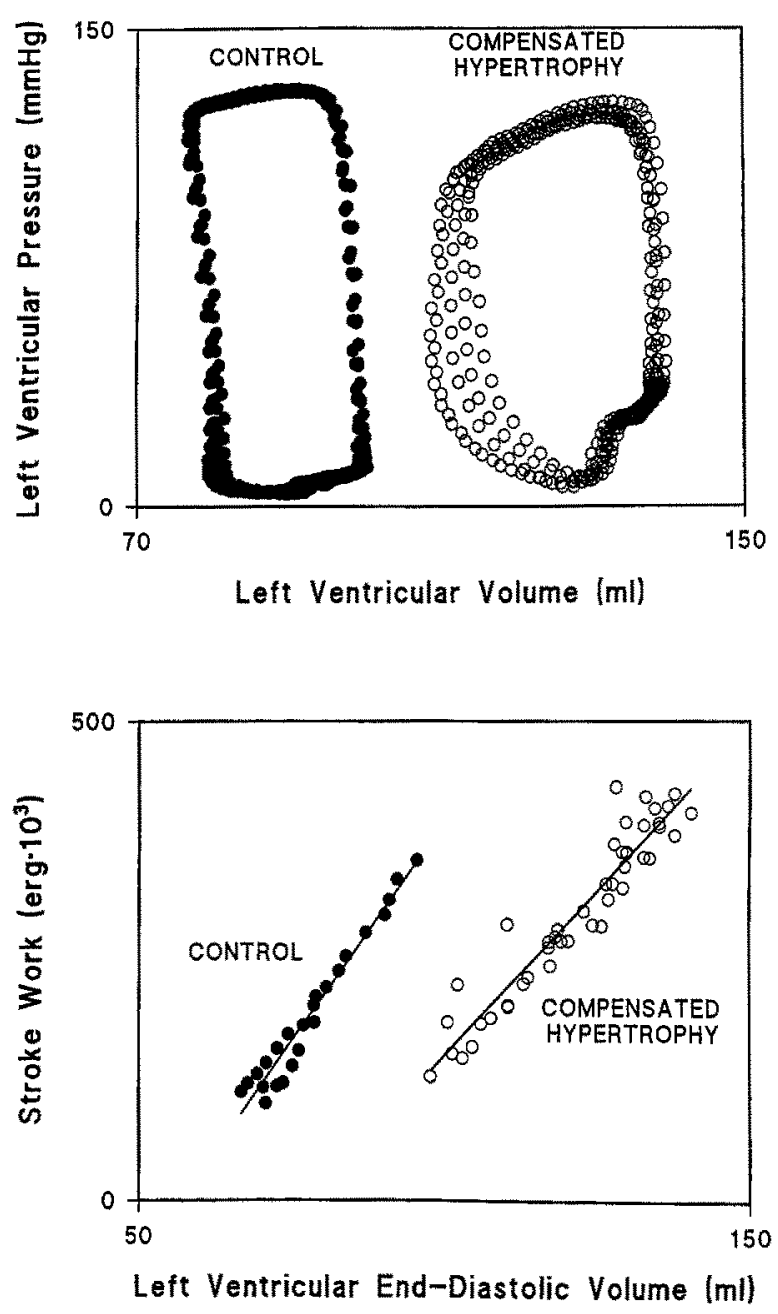

Fig. 2. Representative pressure-volume loops during steady-state (top) and relationships between left ventricular stroke work and Ved during vena caval occlusion for one animal under control conditions and with severe volume overload after 4 weeks of aortic regurgitation.

gm intravenously), anesthetized with intravenous thiamylal sodium ( $25 \mathrm{mg} / \mathrm{kg}$ ), and underwent left thoracotomy under sterile conditions. Hemispheric ultrasonic dimension transducers were placed to measure the epicardial base-apex major and anterior-posterior minor axis diameters of the left ventricle (Fig. 1). ${ }^{9,10}$ Pneumatic occluders were placed on the superior and inferior venae cavae. A silicone rubber catheter was placed in the base of the left atrial appendage, and another catheter with multiple side holes was placed in the pleural space adjacent to the left ventricle for later passage of micromanometers to measure transmural left ventricular pressure. The pericardium was left open. All catheters were exteriorized through a silicone rubber button (Silastic sheeting and tubing, Dow Corning Medical Products) in the skin. The thoracotomy was repaired in layers, and the animals were allowed to recover for 14 days. 
Table I. Effects of early and late aortic regurgitation on left ventricular function $(N=10)$

\begin{tabular}{|c|c|c|c|}
\hline & Control & Early & Late \\
\hline Ved (ml) & $115 \pm 33$ & $132 \pm 34(p=0.002)$ & $127 \pm 38(p=0.05)$ \\
\hline Vwall (ml) & $78 \pm 13$ & $81 \pm 14(p=0.05)$ & $88 \pm 16(p=0.001)$ \\
\hline Vwall/Ved & $0.71 \pm 0.20$ & $0.64 \pm 0.15(p=0.01)$ & $0.73 \pm 0.19$ \\
\hline HR (beats/min) & $107 \pm 20$ & $110 \pm 25$ & $110 \pm 21$ \\
\hline $\mathrm{CO}(\mathrm{L} / \mathrm{min})$ & $3.1 \pm 0.8$ & $4.0 \pm 1.0(p=0.02)$ & $3.7 \pm 1.1(p=0.03)$ \\
\hline $\mathrm{SV}(\mathrm{ml})$ & $31 \pm 12$ & $38 \pm 14(p=0.001)$ & $35 \pm 11$ \\
\hline Ped $(\mathrm{mm} \mathrm{Hg})$ & $13 \pm 4$ & $26 \pm 8(p=0.001)$ & $24 \pm 10(p=0.01)$ \\
\hline$\sigma e d(\mathrm{~mm} \mathrm{Hg})$ & $38 \pm 9$ & $79 \pm 25(p=0.001)$ & $69 \pm 26(p=0.01)$ \\
\hline$\sigma \mathrm{ps}(\mathrm{mm} \mathrm{Hg})$ & $336 \pm 30$ & $369 \pm 55(p=0.04)$ & $340 \pm 58$ \\
\hline oms (mm Hg) & $290 \pm 25$ & $317 \pm 44(p=0.02)$ & $292 \pm 44$ \\
\hline$\sigma \mathrm{ee}(\mathrm{mm} \mathrm{Hg})$ & $275 \pm 25$ & $295 \pm 41$ & $275 \pm 45$ \\
\hline SWlv (erg $\cdot 103)$ & $435 \pm 130$ & $565 \pm 219(p=0.02)$ & $512 \pm 161(p=0.03)$ \\
\hline $\mathrm{Mw}\left(\mathrm{erg} \cdot \mathrm{cm}^{-3} \cdot 10^{3}\right)$ & $6.5 \pm 1.6$ & $7.8 \pm 1.5(p=0.005)$ & $7.1 \pm 1.2$ \\
\hline Vo $(\mathrm{ml})$ & $47 \pm 20$ & $60 \pm 22(p=0.001)$ & $54 \pm 22(p=0.03)$ \\
\hline $\operatorname{Mmp}\left(\mathrm{mW} \cdot \mathrm{cm}^{-3}\right)$ & $24 \pm 8$ & $35 \pm 14(p=0.001)$ & $29 \pm 12$ \\
\hline Ees $(\mathrm{mm} \mathrm{Hg} / \mathrm{ml})$ & $1.7 \pm 0.6$ & $1.4 \pm 0.5$ & $1.4 \pm 0.5$ \\
\hline $\mathrm{Vd}(\mathrm{ml})$ & $15 \pm 19$ & $9 \pm 35$ & $-40 \pm 138$ \\
\hline Ees $\cdot$ Ved $(\mathrm{mm} \mathrm{Hg})$ & $127 \pm 41$ & $113 \pm 35$ & $121 \pm 68$ \\
\hline Ees $\cdot$ Vwall $(\mathrm{mm} \mathrm{Hg})$ & $181 \pm 46$ & $151 \pm 53$ & $170 \pm 82$ \\
\hline
\end{tabular}

All data are mean plus or minus standard deviation; $p$ values shown are compared with control values by Dunnett's $t$ test. $H R$, Heart rate; $C O$, total cardiac output; $S V$, stroke volume; $P e d$, end-diastolic pressure; $\sigma m s$, mean systolic stress; $\sigma e e$, end ejection stress; $S W l v$, stroke work; $M w$, slope of stroke work-Ved relationship; Vo, $\mathrm{x}$-intercept of stroke work-Ved relationship; $V d$, x-intercept of end-systolic pressure volume relationship.

Before the creation of aortic regurgitation, each animal underwent a control study in the conscious, unsedated state. The dimension transducers were coupled to a sonomicrometer (Physiologic Monitoring Systems, Durham, N.C.). The velocity of sound in the intact canine heart was considered to be $1580 \mathrm{~m} / \mathrm{sec}^{11}$ Sterile micromanometers (model MPC-500, Millar Instruments, Houston, Tex.) that had been zeroed to atmospheric pressure and electronically calibrated were passed through the implanted catheters into the left ventricle and pleural space. Physiologic data were recorded under steady-state conditions and during transient vena caval occlusions.

Two-dimensional echocardiography was done from the right lateral chest wall with the animal lying on its right side on a table with a cutout for access. A $5 \mathrm{MHz}$ short-focus transducer (model 77020A, Hewlett-Packard, Andover, Mass.) was used to acquire a long-axis view through the plane of the mitral valve and a short-axis view at the level of the midpapillary muscles, which were recorded on videotape for later analysis. ${ }^{12}$ Care was taken to obtain the short-axis view with maximal circularity at end diastole and to ensure that the same image was obtained at each study.

After the control study, aortic regurgitation was created in each animal by use of a modification of the method of Leshin and Horwitz. ${ }^{13}$ After general anesthesia was induced (thiamylal sodium, $25 \mathrm{mg} / \mathrm{kg}$ intravenously), a modified Brockenbrough catheter was introduced through a right carotid arteriotomy and was passed to the left coronary cusp under fluoroscopic guidance. The cusp was punctured with a stiff wire and the catheter advanced over the wire through the cusp into the ventricle. The wire was replaced with a $4 \mathrm{~F}$ Fogarty thromboembolectomy catheter. The balloon was inflated and withdrawn, creating a laceration of the cusp. The procedure was repeated as necessary to produce mild to moderate aortic valvular incompetence, verified by aortic root contrast injection. After creation of aortic regurgitation, each animal was studied at intervals of 1 to 3 weeks with a protocol identical to that of the control study. At the conclusion of the study period, general anesthesia was induced with thiamylal sodium ( $50 \mathrm{mg} / \mathrm{kg}$ intravenously), and the heart arrested with intravenous potassium chloride.

Data analysis. All data were filtered by a $50 \mathrm{~Hz}$ lowpass analog filter and digitized in real time at an eightchannel sweep speed of $200 \mathrm{~Hz}$ by an analog-to-digital converter (model 1012, ADAC, Woburn, Mass.). Data analysis was done on a microprocessor (MicroVAX II/ GPX Work Station, Digital Equipment Corp., Maynard, Mass.) with interactive prograrns. Left ventricular transmural pressure was calculated as the difference between left ventricular and pleural pressures, and all left ventricular pressures are presented as transmural pressures. The first time derivative of left ventricular transmural pressure $(\mathrm{dP} / \mathrm{dt})$ was computed from the digital pressure waveform as a running five-point polyorthogonal transformation. The cardiac cycle was defined automatically with $\mathrm{dP} / \mathrm{dt}$ as previously described. ${ }^{10}$ Beginning ejection was placed 10 msec after peak positive $\mathrm{dP} / \mathrm{dt}$, whereas end ejection was defined as peak negative $\mathrm{dP} / \mathrm{dt}$. Diastole was defined to begin with the first zero crossing of $\mathrm{dP} / \mathrm{dt}$ after peak negative $\mathrm{dP} / \mathrm{dt}$, and diastole ended $40 \mathrm{msec}$ before a positive $\mathrm{dP} / \mathrm{dt}$ greater than $500 \mathrm{~mm} \mathrm{Hg} / \mathrm{sec}$. Beat point definitions were checked and corrected if necessary with a videographic display system.

Myocardial wall volume (Vwall) was determined with use of a previously validated echocardiographic technique. ${ }^{12}$ During playback of the recorded image, enddiastolic and end-systolic freeze-frame images were analyzed by the leading-edge method. Digital light pen 

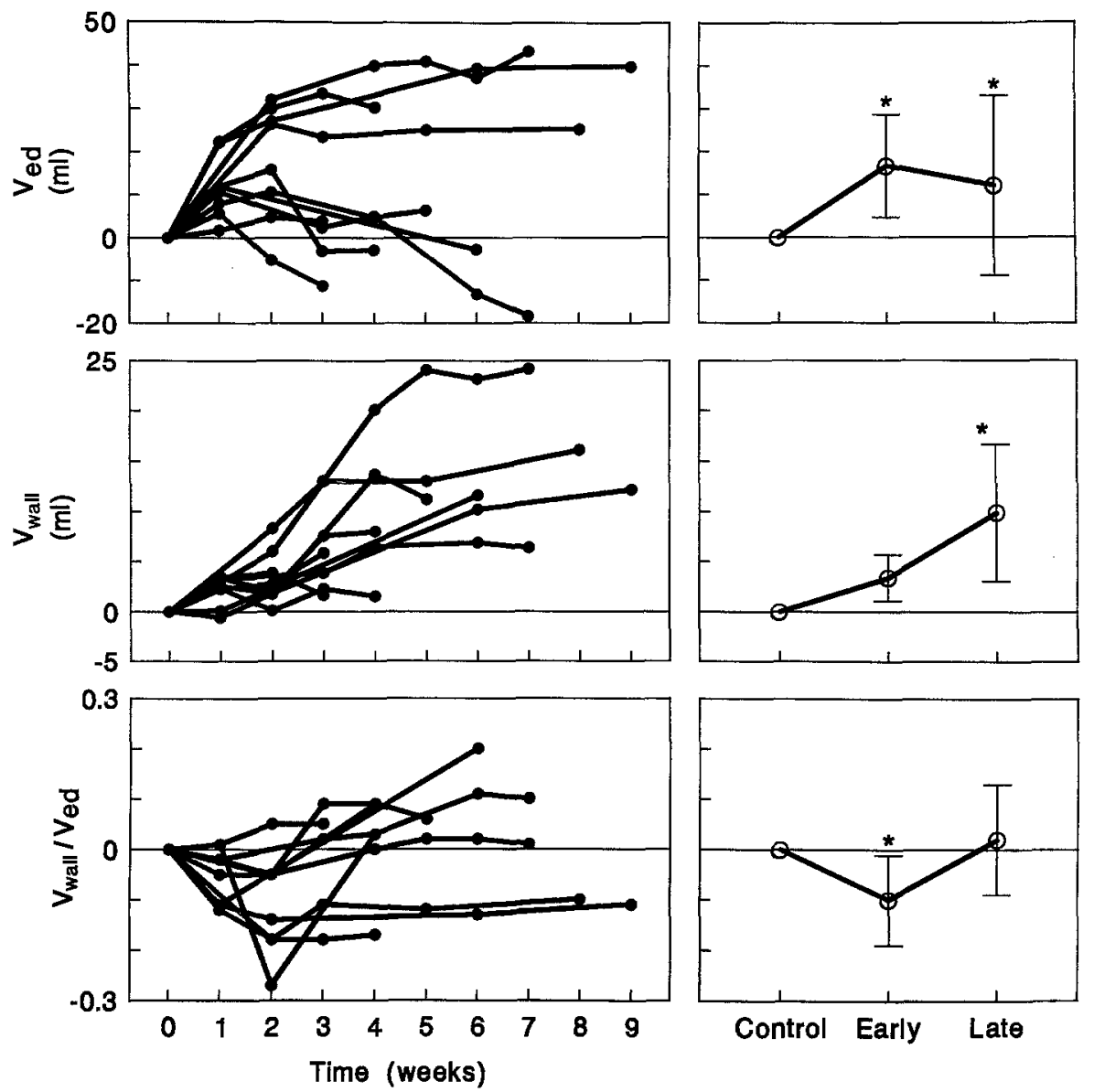

Fig. 3. Change from control values of Ved, Vwall, and the ratio Vwall/Ved for each animal over time (left panels), and mean plus or minus standard deviation for all animals at early and late studies (right panels). ${ }^{*} p<0.05$ versus control value.

planimeters were used to trace the short-axis epicardial and endocardial borders excluding the papillary muscles and to measure the long-axis length from the midpoint of the mitral annular plane to the epicardium at the apex. ${ }^{12}$ Feneley and associates ${ }^{12}$ have demonstrated that the average of the product of the echocardiographic myocardial cross-sectional area (Amyo) and the epicardial longaxis length (Lo) at end diastole (ed) and end systole (es) accurately estimates Vwall in normal and volume overloaded dogs:

$V_{\text {wall }}=[($ ed Amyo $\times$ edLo $)+($ es Amyo $\times$ esLo $)] / 2$

Left ventricular cavitary volume $(\mathrm{V})$ was calculated from epicardial major (a) and minor (b) axis diameters by representing the epicardial surface of the left ventricle as a cylindrical shell ${ }^{11}$ and subtracting the ventricular wall volume ( $V$ wall):

$$
\mathrm{V}(\mathrm{ml})=(\pi / 4) \mathrm{b} 2 \mathrm{a}-\text { Vwall }
$$

Cardiac function was assessed by stroke volume, total cardiac output, stroke work, and stroke work under steady-state conditions at each study point. Total cardiac output represents the blood ejected by the ventricle and is the sum of the forward cardiac output and the regurgitant volume. Regurgitant volume was not measured in this study. Midwall latitudinal stress was calculated according to the methods of Regen ${ }^{14}$ (appendix).

Ventricular performance was assessed with use of the linear Frank-Starling relationship between stroke work and left ventricular end-diastolic volume (Ved) characterized by the slope $(\mathrm{Mw})$ and $\mathrm{x}$-intercept (Vo). ${ }^{15}$ There lationship between end-systolic pressure and end-systolic volume was also examined. To adjust for variations in ventricular geometry and size, myocardial performance was assessed by the use of the slope of the linear regression between myocardial power output and end-diastolic circumferential strain (Mmp) ${ }^{15}$ (appendix).

Statistical analysis. Animals were studied at intervals of 1 to 3 weeks. To facilitate statistical analysis, studies were grouped into three times: control, early, and late after creation of aortic regurgitation. The early point was chosen as the study during weeks 1 to 3 with maximal dilation. The late point was defined as the final study for 

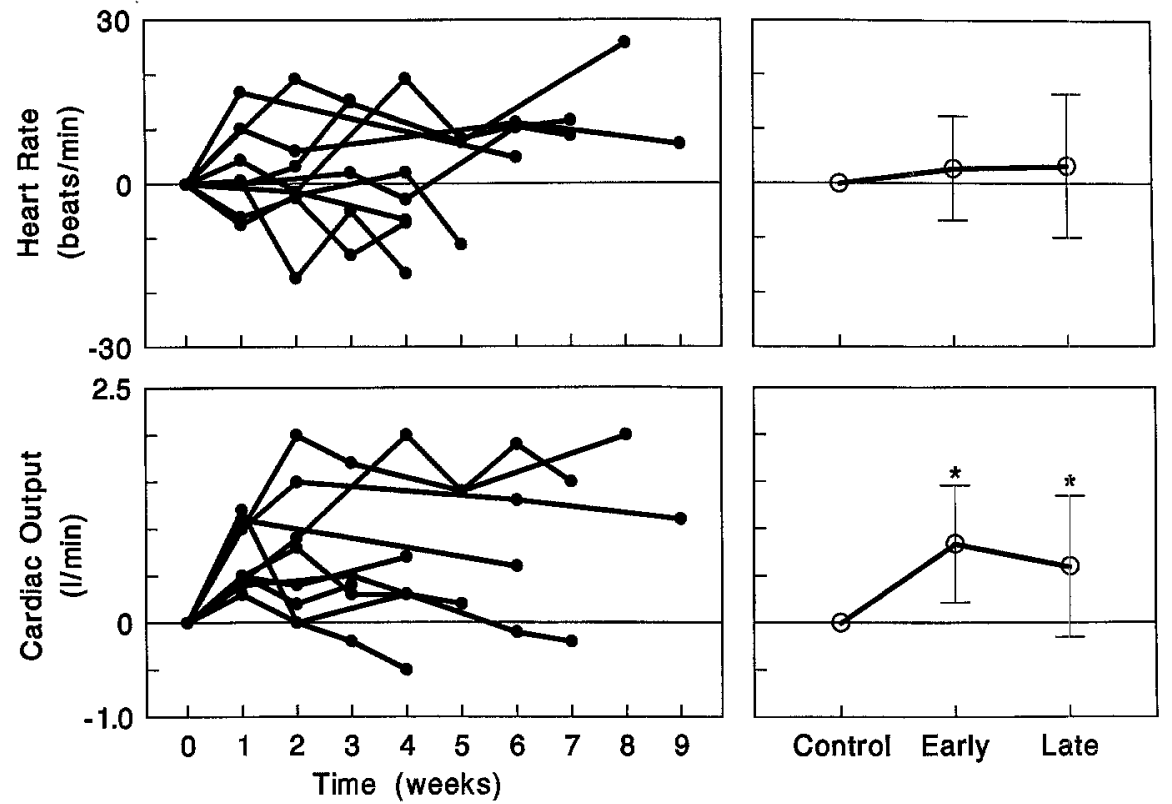

Fig. 4. Change from control values of heart rate and total cardiac output for each animal over time (left panels), and mean plus or minus standard deviation for all animals at early and late studies (right panels). ${ }^{*} p<0.05$ versus control values.

each animal (weeks 4 to 9). Similar methods have been used in previous studies of adaptation to volume overload. ${ }^{8}$ For each variable, repeated-measures multivariate analysis of variance was done to determine whether a time effect was present. Each animal was entered into the model once, to ensure independence. Quadratic terms were tested for all variables found to be insignificant, confirming linearity of the model. When a difference across time by multivariate analysis of variance could be demonstrated at the 0.05 level, differences between individual times and control values were assessed by Dunnett's $t$ test (SAS, version 6.07, SAS Institute, Cary, N.C.). All results are expressed as mean plus or minus the standard deviation.

\section{Results}

The mean duration of aortic regurgitation at the time of the early study was $1.9 \pm 0.7$ weeks and at the final study $5.7 \pm 2.0$ weeks. The hemodynamic data are summarized in Table I. Left ventricular adaptation to aortic regurgitation was characterized by initial left ventricular dilation followed by compensatory hypertrophy (Figs. 2 and 3 ). Changes in heart rate and total cardiac output are shown in Fig. 4. Early and sustained left ventricular dilation assessed by Ved and unstressed volume correlated temporally with increased end-diastolic wall stress (ored). Peak systolic stress ( $\sigma p s$ ) and mean systolic stress were initially elevated but returned to control levels after the development of hypertrophy (Fig. 5).
Decompensated failure was not observed in any of the animals in this study. The slope of the stroke work-Ved relationship ( $\mathrm{Mw}$ ) increased at the early study, but returned toward control levels by the final study (Table I, Fig. 6). Intrinsic myocardial performance, as assessed by Mmp, increased significantly at the early study and returned to control levels by the final study (Table I, Fig. 6).

\section{Discussion}

No experimental model perfectly mimics clinical aortic regurgitation, which usually increases in severity over a period of years. In many studies of volume overload, a severe lesion was abruptly created to produce significant hypertrophy or congestive heart failure in a short time, yet the onset and severity of the lesion may alter the adaptive response of the ventricle. Grossman and colleagues ${ }^{3}$ compared the patterns of ventricular hypertrophy in pressure overload and volume overload. In patients with volume overload, ops values were generally normal, but $\sigma e d$ values were elevated with a normal ratio of wall thickness to radius. The authors proposed that elevation of ops as a result of pressure overload stimulated concentric hypertrophy without dilation, promoting parallel replication of sarcomeres and return of $\sigma \mathrm{ps}$ to normal. Increased $\sigma \mathrm{ed}$ 

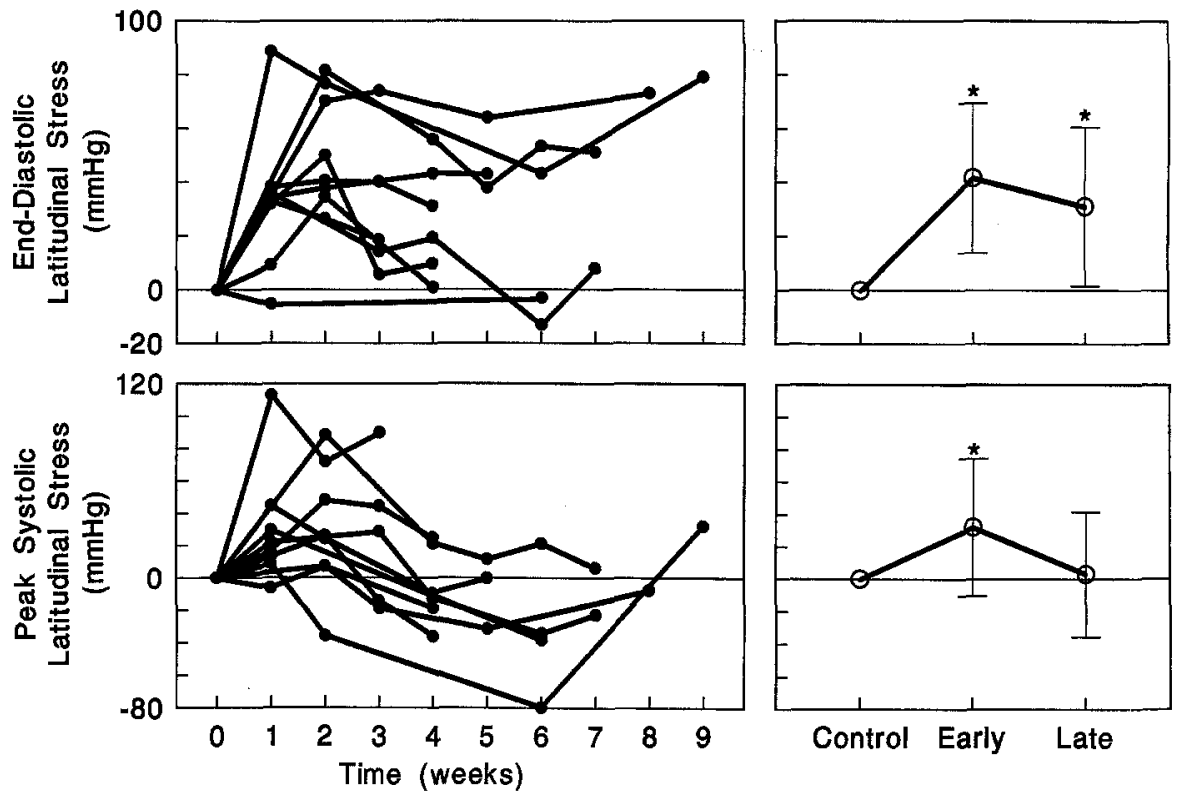

Fig. 5. Change from control values of left ventricular end-diastolic and peak systolic latitudinal wall stress for each animal (left panels), and mean plus or minus standard deviation for all animals at early and late studies (right panels). * $p<0.05$ versus control values.

was proposed to stimulate ventricular dilation. Chronic dilation that persists after the development of compensated hypertrophy may result in part from series replication of sarcomeres, with parallel replication accounting for the increase in wall thickness. The initial dilation elevates systolic stress and therefore stimulates wall thickening sufficient to return systolic stress to normal. A similar index relating the degree of hypertrophy to the degree of dilation is the ratio of Vwall to end-diastolic cavitary volume. ${ }^{6}$ A fall in either the ratio of wall thickness to radius or Vwall/Ved suggests dilation with inadequate hypertrophy, whereas an increase to greater than control levels suggests "excess hypertrophy" as seen in pressure overload states. In the current study, Vwall/Ved values fell initially as ventricular dilation predominated and returned to control levels as hypertrophy developed. The sequence of increased ops followed by compensatory ventricular hypertrophy sufficient to decrease ops and normalize Vwall/ Ved is consistent with a feedback mechanism linking systolic wall stress and hypertrophy. ${ }^{3}$

Lee and associates ${ }^{7}$ found that values of $\sigma e d$ and ops increased after the creation of mitral regurgitation. Although diastolic and systolic stress decreased after the development of hypertrophy, both remained elevated compared with control values after 4 weeks, which suggested a stable degree of hyper- trophy might not have been achieved. Crozatier and colleagues $^{5}$ studied dogs 24 hours after the creation of aortic regurgitation and found elevated $\sigma \mathrm{ps}$ values with decreased end-systolic wall stress, which suggested that changes in end-systolic wall stress may not accurately reflect changes in ops. Florenzano and Glant $z^{2}$ noted that after the creation of aortic regurgitation in chronically instrumented dogs, $\sigma e d$ values increased and gradually returned towar control levels but remained elevated at 3 months. End-systolic stress tended to increase over the course of the study but failed to reach statistical significance and ops values were not reported. Magid and colleagues ${ }^{15}$ found an increase in values of end-systolic wall stress in rabbits with mild to moderate aortic regurgitation at 6 months to 1 year.

Results of most prior studies of myocardial performance in volume overload are consistent with unchanged myocardial performance in the early, compensated phases. $^{8}$ Florenzano and Glantz ${ }^{2}$ examined ventricular function in dogs with aortic regurgitation with use of the slope of the endsystolic pressure-volume relationship (Ees) before and after $\beta$-adrenergic blockade. Ees values were normalized for changes in ventricular size by multiplying by ventricular mass (Vwall). Both Ees and the corrected slope (Ees - Vwall) increased after creation of aortic regurgitation and remained elevated 

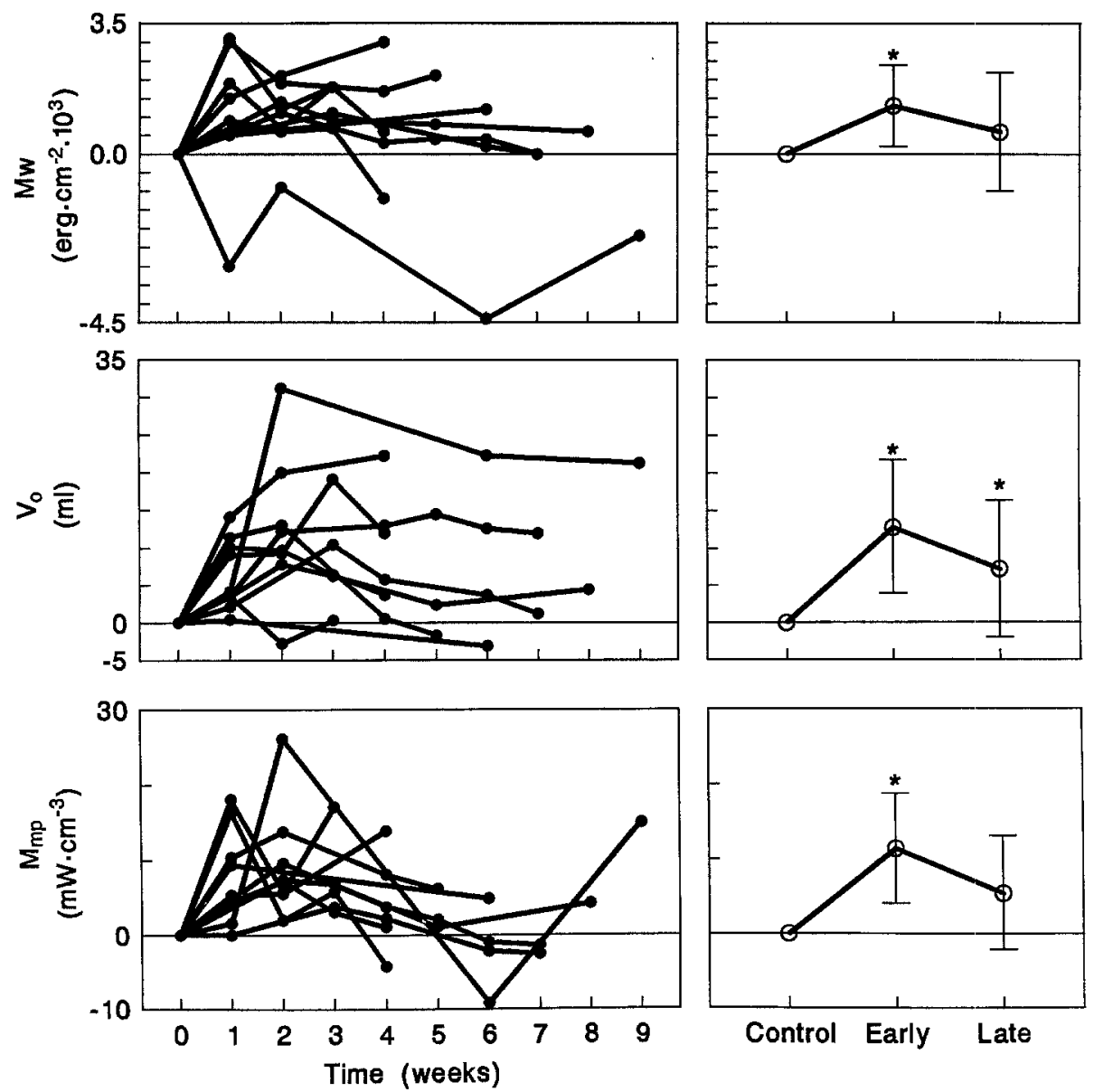

Fig. 6. Change from control values of slope $(M w)$ and $\mathrm{x}$-intercept $(\mathrm{Vo})$ of stroke work versus end-diastolic volume relationship and Mmp. Data are shown for each animal (left panels), and mean plus or minus standard deviation for all animals at early and late studies (right panels). ${ }^{*} p<0.05$ versus control values.

throughout the study. Magid and associates ${ }^{15,16}$ demonstrated preserved systolic function at 6 months to 2.5 years in rabbits with mild to moderate aortic regurgitation whereas in animals with severe aortic regurgitation evidence of systolic dyfunction developed. In the current study, Ees and the corrected indices Ees - Ved and Ees - Vwall were not significantly altered after the creation of aortic regurgitation, which suggests unchanged ventricular function. However, because other indices (stroke work under steady-state conditions, stroke volume, total cardiac output, and $\mathrm{Mw}$ ) all suggested improved ventricular function, the lack of significant change in end-systolic parameters may simply result from increased ventricular size despite attempts at correction. Given that the values of $\sigma p s$ and mean systolic stress did increase but values of end-systolic wall stress did not, measurement of ventricular elastance at end systole may not be an appropriate measure of overall ventricular systolic performance in this type of volume overload.

Starling and associates ${ }^{17}$ examined ventricular function and myocardial performance in patients with aortic regurgitation with use of Ees and the circumferential stress-shortening relationship and were able to define distinctions between ventricular performance and myocardial performance in three groups of patients. Group I had normal ventricular function and myocardial performance with a normal volume/mass ratio (the inverse of $\mathrm{Vwall} / \mathrm{Ved}$ ). Group II had left ventricular dysfunction (abnormal Ees) with maintained myocardial performance and an increase in the volume/mass ratio, suggesting dilation with inadequate hypertrophy. Group III 
showed abnormal ventricular function and myocardial performance and had the worst results after aortic valve replacement.

$\mathrm{Mmp}$ is a sensitive measure of myocardial performance. ${ }^{9}$ Serial assessment of $\mathrm{Mmp}$ in patients may aid in the timing of aortic valve replacement. A decline in Mmp to less than baseline values would indicate the onset of myocardial dysfunction and valve replacement should be done. As long as myocardial function is preserved after valve replacement, we would anticipate regression of the left ventricular hypertrophy and normalization of wall stress. Further studies in patients with aortic regurgitation will be necessary to confirm the utility of assessment of Mmp.

The current study has several advantages over previous studies. No previous studies have provided load-insensitive measures of ventricular function and myocardial performance in serial studies of conscious, closed-chest animals with control data before and after creation of aortic regurgitation. The use of modified Frank-Starling analyses in the present study (equations 13, 14, and 15 in the appendix) allowed examination of both ventricular function and myocardial performance with adjustment for altered ventricular geometry and size. The Mmp relationship is insensitive to changes in afterload and is normalized by the use of wall stress and circumferential strain measurements to account for differences in ventricular size and geometry. The use of modified Frank-Starling analyses avoided the difficulties of limited data range and nonlinearity of end-systolic analyses. ${ }^{18}$ By examining $\sigma p s$ as opposed to end-systolic wall stress, the present study detected an early increase in systolic stress that normalized with the onset of hypertrophy, consistent with the Grossman hypothesis. ${ }^{3}$

Although the current study provides unique data not previously available, there are limitations. Chronic ventricular adaptation to aortic regurgitation over many years may differ from adaptation over the short period of the current study. No hearts in the current study showed the massive degree of hypertrophy and dilation occasionally seen clinically, yet the hypertrophy and dilation observed in the present study were consistent with that seen clinically with mild to moderate subacute aortic regurgitation. At the late study, myocardial function had returned to control levels and Vwall/Ved values had normalized. However, the late study point may not represent the final compensated state of more chronic aortic regurgitation and additional myocar- dial adaptation might occur. These limitations were a result of the degree of aortic regurgitation created and the limited time over which chronic animal instrumentation can be maintained. However, the present study does provide insight into the acute and compensated stages of aortic regurgitation. The degree of aortic regurgitation was not quantified precisely in this study, but this technique for creation of aortic regurgitation produces a consistent degree of aortic regurgitation. ${ }^{13}$ Measurement of left ventricular cavitary volume from dimensional data requires assumptions concerning the geometric shape of the ventricle. Adaptation to severe aortic regurgitation results in significant alterations of ventricular geometry. Previous studies in our laboratory have demonstrated that no significant changes in ventricular geometry occur with the degree of aortic regurgitation created in this study. ${ }^{11}$ The cylindrical model used to calculate left ventricular cavitary volume (equation 2) was shown to accurately measure left ventricular cavitary volume in normal animals and animals with aortic regurgitation. ${ }^{11}$ The cylindrical model overestimates cavitary volume by approximately $40 \mathrm{ml}$. Although this overestimate affects the absolute values of ventricular volumes, volume intercepts, $\mathrm{Mw}$, and $\mathrm{Ees}$, it does not affect stress- and dimension-based calculations such as Mmp. ${ }^{11}$ This volume overestimate is constant and independent of cavitary volume and wall volume for each animal. ${ }^{11}$ The cylindrical model has been shown to be the only model that accurately calculates changes in left ventricular cavitary volume in the presence of altered wall volume caused by hypertrophy. ${ }^{11}$ The variability in measurements among animals is multifactorial and represents biologic variability, differences in transducer placement, and the response to aortic regurgitation. The current study focused on changes over time in serial measurements, whereas the absolute volumes were less important. The estimations of ventricular function and myocardial performance were based on assumptions regarding left ventricular geometry and wall stresses. These models have been examined and validated within the limits of measurement techniques, ${ }^{9-11,14,19}$ and errors resultant from these models are unlikely to change the directional effects sought in this study. ${ }^{10,14,19}$

We gratefully acknowledge the secretarial and editorial assistance of Louise Leighton and Judith M. Karpinen. We appreciate the technical aid of Ruth Rogers and the statistical advice of Lawrence $\mathrm{H}$. Muhlbaier, $\mathrm{PhD}$. 


\section{REFERENCES}

1. Carabello BA. The changing unnatural history of valvular regurgitation. Ann Thorac Surg 1992;53:191-9.

2. Florenzano F, Glantz SA. Left ventricular mechanical adaptation to chronic aortic regurgitation in intact dogs. Am J Physiol 1987;252:H969-84.

3. Grossman W, Jones D, McLaurin LP. Wall stress and patterns of hypertrophy in the human left ventricle. J Clin Invest 1975;56:56-64.

4. Carabello BA, Nakano K, Corin W, Biederman R, Spann JF Jr. Left ventricular function in experimental volume overload hypertrophy. Am J Physiol 1989;256:H974-81.

5. Crozatier B, Caillet D, Chevrier JL, Hatt PY. Nonsympathetic increased inotropic state early after aortic insufficiency. Am J Physiol 1982;242:H973-9.

6. Kleaveland JP, Kussmaul WG, Vinciguerra T, Diters R, Carabello BA. Volume overload hypertrophy in a closedchest model of mitral regurgitation. Am J Physiol 1988;254: H1034-41.

7. Lee JD, Sasayama S, Kihara Y, Ohyagi A, Fujisawa A, Yui Y. Adaptations of the left ventricle to chronic volume overload induced by mitral regurgitation in conscious dogs. Heart Vessels 1985;1:9-15.

8. Ross J Jr. Adaptations of the left ventricle of chronic volume overload. Circ Res 1974;34,35(suppl II):64-70.

9. Glower DD, Spratt JA, Snow ND, et al. Linearity of the Frank-Starling relationship in the intact heart: the concept of preload recruitable stroke work. Circulation 1985;71:9941009.

10. Rankin JS, McHale PA, Arentzen CE, Ling D, Greenfield JC $\mathrm{Jr}$, Anderson RW. The three-dimensional dynamic geometry of the left ventricle in the conscious dog. Circ Res 1976;39: 304-13.

11. Gaynor JW, Feneley MP, Gall SA Jr, et al. Measurement of left ventricular volume in normal and volume-overloaded canine hearts. Am J Physiol 1994;266:H329-40.

12. Feneley MP, Gaynor JW, Maier GW, Gall SA Jr, Kisslo JA, Rankin JS. In vivo estimation of left ventricular wall volume in volume-overloaded canine hearts. Am J Physiol 1988;255: H1399-404.

13. Leshin SJ, Horwitz LD. A closed-chest catheter technique for producing aortic regurgitation in dogs. J Appl Physiol 1972; 33:693-5.

14. Regen DM. Calculation of left ventricular wall stress. Circ Res 1990;67:245-52.

15. Magid NM, Opio G, Wallerson DC, Young MS, Borer JS. Heart failure due to chronic experimental aortic regurgitation. Am J Physiol 1994;267:H556-62.

16. Magid NM, Wallerson DC, Borer JS, et al. Left ventricular diastolic and systolic performance during chronic experimental aortic regurgitation. Am J Physiol 1992;263:H226-33.

17. Starling MR, Kirsch MM, Montgomery DG, Gross MD. Mechanisms for left ventricular systolic dysfunction in aortic regurgitation: importance for predicting the functional response to aortic valve replacement. J Am Coll Cardiol 1991;17:887-97.

18. Spratt JA, Tyson GS, Glower DD, Davis JW, Muhlbaier LH, Olsen $\mathrm{CO}$. The end-systolic pressure-volume relationship in conscious dogs. Circulation 1987;75:1295-309.

19. McHale PA, Greenfield JC Jr. Evaluation of several geometric models for estimation of left ventricular circumferential stress. Circ Res 1973;33:303-12.

\section{Appendix}

Stroke volume (SV) was calculated as

$$
\mathrm{SV}(\mathrm{ml})=\mathrm{Ved}-\mathrm{Vee}
$$

where Ved is the end-diastolic cavitary volume and Vee is the end-ejection cavitary volume. Total cardiac output (CO) was calculated as

$$
\mathrm{CO}(\mathrm{L} / \mathrm{min})=(\mathrm{SV} \cdot \mathrm{HR}) / 1000
$$

where HR is heart rate in beats per minute. Global left ventricular stroke work (SW) was calculated as the integral of left ventricular transmural pressure $(\mathbf{P})$ and cavitary volume (V) over each cardiac cycle as described by the formula

$$
\mathrm{SW}=\int \mathrm{P} \cdot \mathrm{dV}
$$

Equatorial myocardial wall thickness (h) was calculated using an open-ended cylindrical model

$$
\text { Vwall }=[(\pi / 4) \mathrm{b} 2 \mathrm{a}]-[(\pi / 4)(\mathrm{b}-2 \mathrm{~h}) 2 \mathrm{a}]
$$

where $a$ is the epicardial major axis diameter and $b$ is the epicardial minor axis diameter, and solving the resulting quadratic equation for $h$ :

$$
\mathrm{h}(\mathrm{mm})=(1 / 2)\{\mathrm{b}-\sqrt{\mathrm{b} 2}-[4 \mathrm{Vwall} /(\pi \mathrm{a})]\}
$$

The midwall minor axis circumference $(\mathrm{C})$ was calculated as

$$
\mathrm{C}(\mathrm{mm})=\pi(\mathrm{b}-\mathrm{h})
$$

To normalize for differences in size and geometry between animals and in each animal over time, midwall latitudinal strain $(\epsilon)$ was calculated from midwall circumference (C) as

$$
\epsilon=(\mathrm{C}-\mathrm{Co}) / \mathrm{Co}
$$

where $\mathrm{Co}$ is the unstressed midwall circumference measured at the unstressed left ventricular volume, Vo (the $x$-intercept of the stroke work-Ved relationship) ${ }^{9}$ (equation 13). Midwall latitudinal stress $(\sigma)$ was calculated according to the method of Regen ${ }^{14}$ :

$$
\begin{aligned}
& \sigma(\mathrm{mm} \mathrm{Hg})= \\
& \quad \mathrm{P}(\mathrm{b}-\mathrm{h})\{2-[(\mathrm{b}-\mathrm{h}) 2 /(\mathrm{a}-0.275 \mathrm{~h}) 2]\} /(2 \mathrm{~h})
\end{aligned}
$$

where $\mathbf{P}$ is left ventricular transmural pressure (in millimeters of mercury). The wall thickness ( $h$ ) at the base is assumed to be zero, and wall thickness at the apex is assumed to be $0.55 \mathrm{~h}^{19}$ A normalized minor axis latitudinal stroke work analogue ( $\mathrm{SWn}$ ) was calculated as

$$
\mathrm{SWn}=\int \sigma \cdot \mathrm{d} \epsilon
$$

and myocardial power output (MPO) was calculated as ${ }^{15}$

$$
\mathrm{MPO}=\mathrm{HR} \cdot \int \sigma \mathrm{d} \epsilon=\mathrm{HR} \cdot \mathrm{SWn}
$$

Linear regression analysis was done on data from individual vena caval occlusions, and the data were fitted to the formula

$$
\mathrm{SW}=\mathrm{Mw}(\mathrm{Ved}-\mathrm{Vo})
$$


describing the linear Frank-Starling (SW-Ved) relationship between stroke work (SW) and left ventricular Ved with slope $\mathrm{Mw}$ and $\mathrm{x}$-intercept $\mathrm{Vo}^{15}$

To adjust for variations in ventricular geometry and size, myocardial performance was assessed with the use of Mmp, the slope of the linear regression between myocardial power output (MPO) and end-diastolic circumferential strain $(\epsilon e d)^{15}$ :

$$
\mathrm{MPO}=\mathrm{Mmp} \cdot \epsilon \mathrm{d}
$$

The relationship between end-systolic pressure (Pes) and end-systolic volume (Ves) was also examined. The point of maximal pressure/volume $(\mathrm{P} / \mathrm{V})$ ratio was selected for each beat of a vena caval occlusion. A linear regression was done on the pressure and volume values at this point yielding a slope (E) and an intercept (VE). A single iteration was done with use of the intercept estimate (VE) to choose the points of maximal $[\mathrm{P} /(\mathrm{V}-\mathrm{VE})]$ for each beat. A second linear regression was done to generate a slope (Ees) and volume intercept (Vd), and Ees was considered to be the slope of the relationship between end-systolic pressure and end-systolic volume where

$$
\text { Pes }=\text { Ees }(\text { Ves }- \text { Vd })
$$

To normalize Ees for changes in ventricular size, the products Ees - Ved and Ees - Vwall were calculated for each study point. To assess the relationship between hypertrophy (Vwall) and ventricular dilation (Ved), the ratio Vwall/Ved was calculated at each study point. 